\title{
Hydrogen-bonds structure in poly(2-hydroxyethyl methacrylate) studied by temperature-dependent infrared spectroscopy
}

\author{
Shigeaki Morita * \\ Department of Engineering Science, Osaka Electro-Communication University, Neyagawa, Japan
}

\section{Edited by:}

Young Mee Jung, Kangwon National

University, South Korea

\section{Reviewed by:}

Veronica Ambrogi, Dipartimento di Ingegneria Chimica dei Materiali e Della Produzione Industriale, Italy

Marianna Pannico, Institute of

Chemistry and Technology of

Polymers, Italy

\section{*Correspondence}

Shigeaki Morita, Department of Engineering Science, Osaka

Electro-Communication University,

18-8 Hatsucho, Neyagawa 572-8530

Japan

e-mail: smorita@isc.osakac.ac.jp
Hydrogen-bonds structure in poly(2-hydroxyethyl methacrylate) (PHEMA) were investigated by means of temperature-dependent infrared (IR) spectroscopy. Spectral variations involved with the $\mathrm{OH} \cdots \mathrm{OH}$ and $\mathrm{C}=\mathrm{O} \ldots \mathrm{HO}$ types of hydrogen-bonds were found around the glass transition temperature of $80^{\circ} \mathrm{C}$. Hydrogen-bonds among the hydroxyl groups gradually dissociate with increasing temperature. In contrast, discontinuous variation in the carbonyl bands was observed around the glass transition temperature. An association of the $\mathrm{C}=\mathrm{O} \ldots \mathrm{HO}$ type of hydrogen-bond with increasing temperature above the glass transition temperature was revealed. These were concluded from the present study that hydrogen-bonds among the hydroxyl groups in each side chain terminal suppress the main chain mobility in the polymer matrix below the glass transition temperature, while the dissociation of the $\mathrm{OH} \ldots \mathrm{OH}$ type of hydrogen-bonds induces the association of the $\mathrm{C}=\mathrm{O} \ldots \mathrm{HO}$ type of hydrogen-bond. As a result, the mobility of the main chain is induced by the change in hydrogen-bonds structure at the glass transition temperature.

\section{Keywords: PHEMA, hydrogen-bond, glass transition, infrared spectroscopy}

\section{INTRODUCTION}

Poly(2-hydroxyethyl methacrylate) (PHEMA) contains one carbonyl $(\mathrm{C}=\mathrm{O})$ and one hydroxyl $(\mathrm{OH})$ groups on each side chain (Montheard et al., 1992). The $\mathrm{OH}$ group acts as both proton donor and proton acceptor, while the $\mathrm{C}=\mathrm{O}$ group as only proton acceptor (Jeffrey, 1997; Marechal, 2007). Thus, both $\mathrm{OH} \cdots \mathrm{OH}$ and $\mathrm{C}=\mathrm{O} \cdots \mathrm{HO}$ types of hydrogen-bonds are acceptable in PHEMA. Not only dimer structure $(\mathrm{OH} \cdots \mathrm{OH})$ but also aggregates structure $(\cdots \mathrm{OH} \cdots \mathrm{OH} \cdots \mathrm{OH} \cdots)$ have been found in many systems including liquid alcohols (Kristiansson, 1999; Ohno et al., 2008) and solid polymers (Morita et al., 2008, 2009). Such the hydrogen-bonds structure in polymers plays important roles for their macromolecular functions in artificial polymers (Brunsveld et al., 2001) as well as biopolymers (Watanabe et al., 2006, 2007). Our recent study revealed that $47.3 \%$ of the $\mathrm{OH}$ group on the PHEMA side chain terminal are engaged in the $\mathrm{OH} \cdots \mathrm{O}=\mathrm{C}$ type of hydrogen-bond, while the remaining $53.7 \%$ contributes to the $\mathrm{OH} \cdots \mathrm{OH}$ type of hydrogen-bond at ambient temperature (Morita et al., 2009).

In the present study, change in hydrogen-bonds structure in PHEMA in the vicinity of glass transition temperature was explored by means of temperature-dependent infrared (IR) spectroscopy (Perova et al., 1997; Morita et al., 2008; Morita and Kitagawa, 2010). Although PHEMA is water insoluble, large amounts of water is sorbed into a PHEMA matrix with an equilibrium water content of ca. $40 \mathrm{wt} \%$ (Tanaka et al., 2002). A dry PHEMA solid is brittle, since its glass transition temperature is higher than ambient temperature. On the other hand, a PHEMA hydrogel, i.e., a water sorbed PHEMA, becomes soft material, because its glass transition temperature is reduced to be lower than ambient temperature (Roorda et al., 1988). These imply macromolecular properties in PHEMA are characterized by non-covalent interactions of hydrogen-bonds among the polymer chains as well as the hydrated water molecules.

\section{MATERIALS AND METHODS}

An atactic PHEMA with a viscosity-averaged molecular weight of ca. $3.0 \times 10^{5}$ was purchased from Aldrich and used without further purification. A glass transition temperature of the PHEMA sample evaluated by differential scanning calorimetry (DSC) was $80^{\circ} \mathrm{C}$, which was performed using a PerkinElmer Pyris 6 at a heating rate of $10^{\circ} \mathrm{C} \mathrm{min}^{-1}$. An evidence of crystalline phase in the solid was not detected by DSC, demonstrating that the PHEMA sample used in the present study is amorphous. A film sample was prepared on a calcium fluoride substrate by solvent casting from a methanol solution. A thickness of the film sample was controlled as all the IR signals in an absorbance unit become less than 1 . The film sample was enough dried at an ambient temperature before the measurement. Temperature-dependent IR spectra of the PHEMA film were collected over a temperature range of $25-150^{\circ} \mathrm{C}$ with an increment of $1^{\circ} \mathrm{C}$ using a Fourier transform IR spectrometer (Varian, FTS-3000) equipped with a deuterated triglycine sulfate detector at a nitrogen atmosphere. A total of 128 scans were co-added to obtain each spectrum.

\section{RESULTS}

Figure 1 shows temperature-dependent IR spectra of the PHEMA film. No IR signals arising from the residual solvent of methanol 


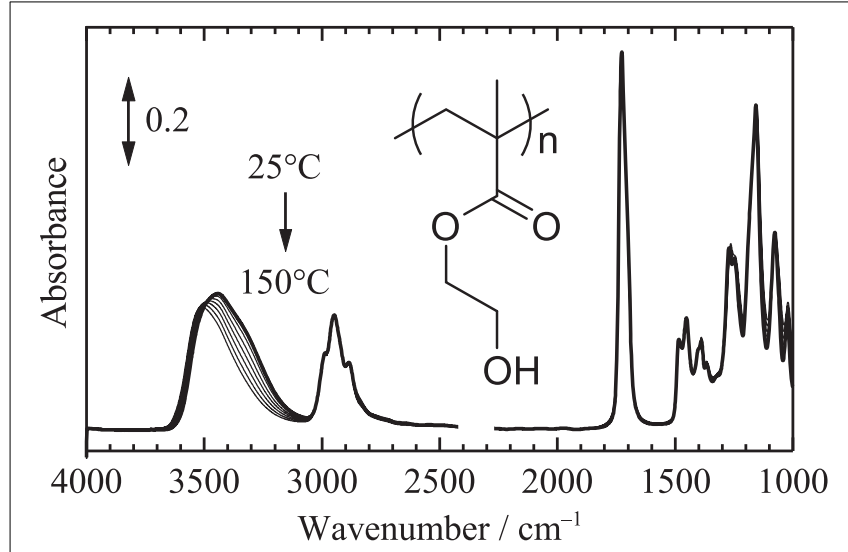

FIGURE 1 | Temperature-dependent IR spectra of PHEMA in the range of $25-150^{\circ} \mathrm{C}$ measured with an increment of $1^{\circ} \mathrm{C}$ (all the spectra are not shown here). Bold line corresponds to the spectrum at $25^{\circ} \mathrm{C}$.

Table 1 | Assignments of selected IR absorption bands in PHEMA.

\begin{tabular}{ll}
\hline Wavenumber/cm & Assignments \\
\hline 3666 & Free $\mathrm{OH}$ (trans) \\
3624 & Free $\mathrm{OH}$ (gauche) \\
3534 & Hydrogen-bonded $\mathrm{OH}$ with $\mathrm{C}=\mathrm{O}(\mathrm{OH} \cdots \mathrm{O}=\mathrm{C})$, \\
& dimer $\mathrm{OH}(\mathrm{OH} \cdots \mathrm{OH})$ \\
3434 & First overtone of $\mathrm{C}=\mathrm{O}$ stretching \\
3320 & Aggregates $\mathrm{OH}(\cdots \mathrm{OH} \cdots \mathrm{OH} \cdots \mathrm{OH} \cdots)$ \\
1730 & Free $\mathrm{C}=\mathrm{O}$ \\
1703 & Hydrogen-bonded $\mathrm{C}=\mathrm{O}$ with $\mathrm{OH}(\mathrm{C}=\mathrm{O} \cdots \mathrm{HO})$
\end{tabular}

and hydrated water from ambient air were detected, representing that a sufficiently dry film was obtained at the nitrogen atmosphere. This represents $\mathrm{O}-\mathrm{H}$ stretching band in the spectra is arising from only PHEMA. Assignments of IR absorption bands in the spectrum of PHEMA have been reported previously (Ferreira et al., 2000; Morita et al., 2009). The assignments are summarized in Table 1. A large spectral shape variation in the $\mathrm{O}-\mathrm{H}$ stretching region around $3700-3100 \mathrm{~cm}^{-1}$ was observed, while only weak variations were detected in the other spectral regions. Detailed spectral variations in the O$\mathrm{H}$ stretching and the $\mathrm{C}=\mathrm{O}$ stretching regions are discussed below.

\section{0-H STRETCHING REGION}

Figure 2A shows the temperature-dependent IR spectra of PHEMA in the $\mathrm{O}-\mathrm{H}$ stretching region (close up of Figure 1). Second derivative spectra calculated from the obtained spectra shown in Figure 2A and peak positions of the second derivative spectra plotted as a function of temperature are also depicted in Figures 2B,C, respectively. At least five contributions around $3666,3624,3534,3434$, and $3320 \mathrm{~cm}^{-1}$ are identified in the O$\mathrm{H}$ stretching region. Our recent study using model compounds of methanol, methyl acetate and 2-hydroxyethyl methacrylate monomer revealed their assignments as summarized in Table 1 (Morita et al., 2009). Although very weak signals in the obtained
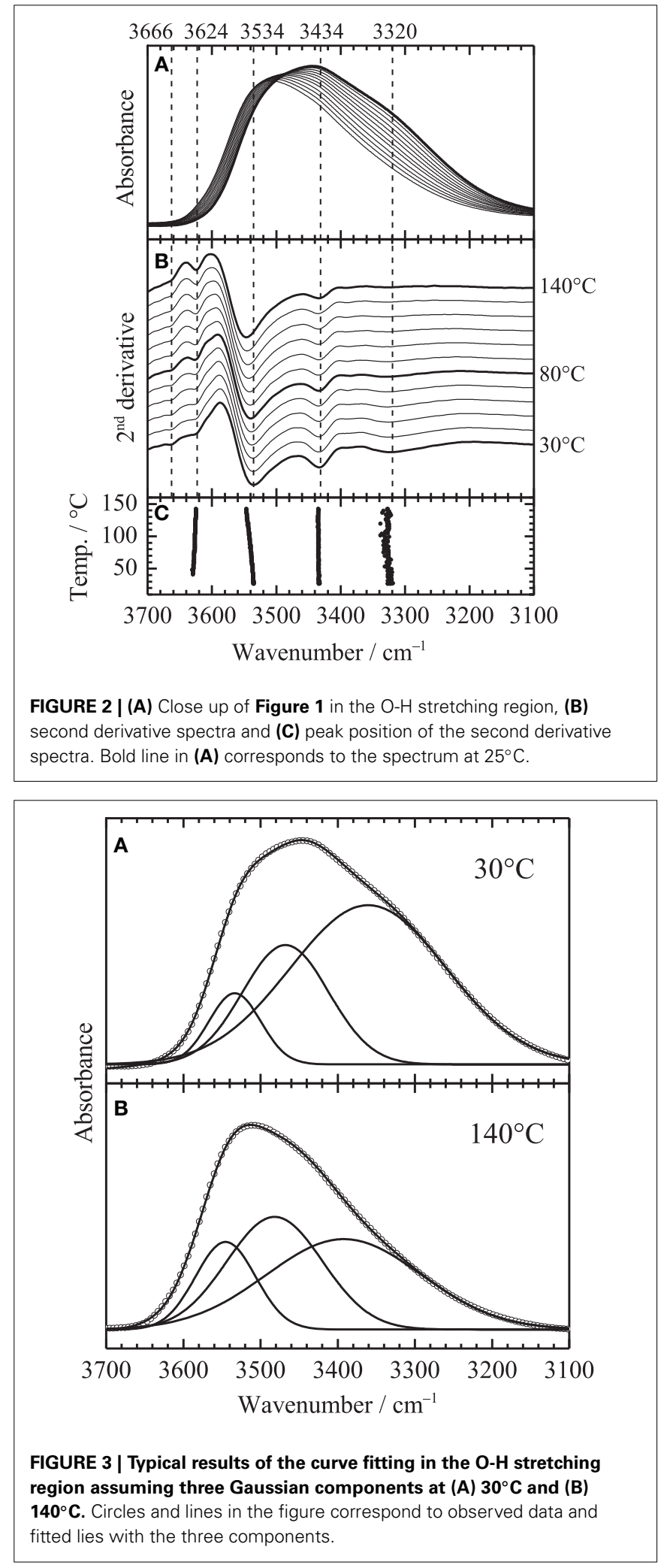

spectra, the bands arising from free $\mathrm{OH}$, i.e., $\mathrm{OH}$ group not donating hydrogen-bond, are clearly identified at 3666 and $3624 \mathrm{~cm}^{-1}$ in the second derivative spectra above the glass transition temperature of $80^{\circ} \mathrm{C}$. 


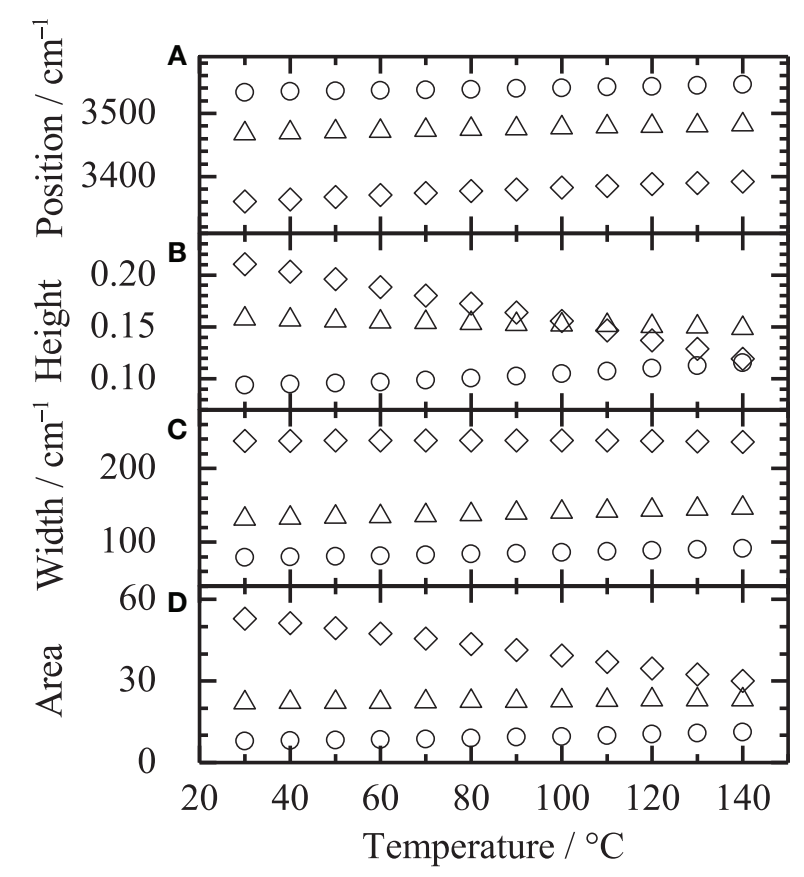

FIGURE 4 | Fitting parameters of (A) peak position, (B) peak height, (C) peak width and $(D)$ area intensity in the $\mathrm{O}-\mathrm{H}$ stretching region plotted as a function of temperature. Symbols of circle, triangle and diamond correspond to the bands around $3534,3434,3320 \mathrm{~cm}^{-1}$, respectively.

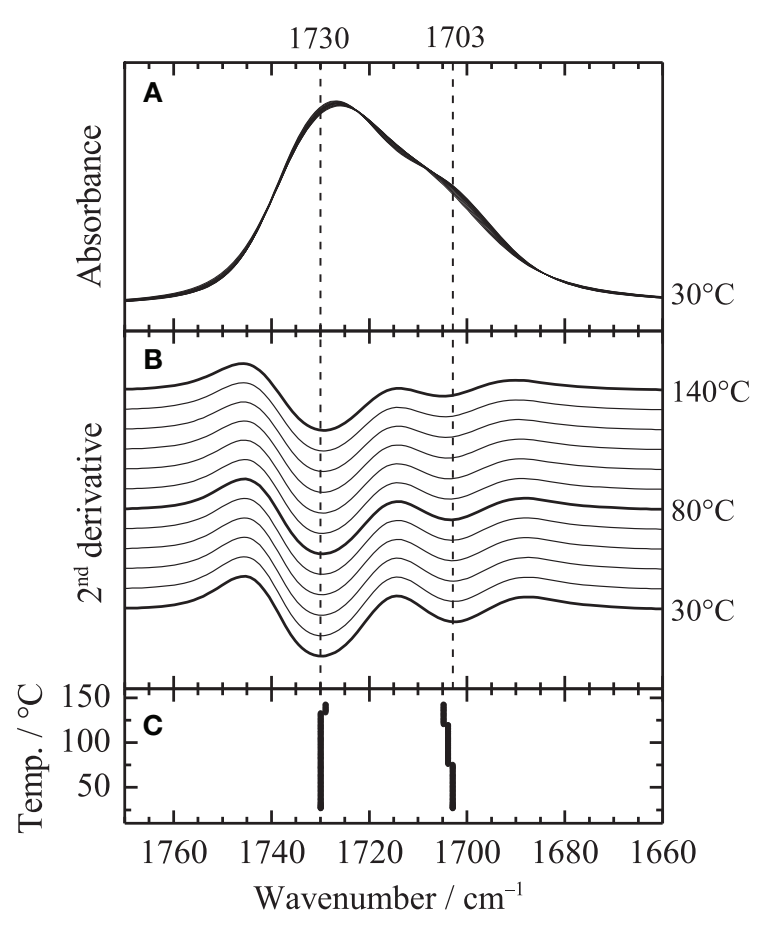

FIGURE 5 | (A) Close up of Figure $\mathbf{1}$ in the $\mathrm{C}=\mathrm{O}$ stretching region, (B) second derivative spectra and $(\mathbf{C})$ peak position of the second derivative spectra.

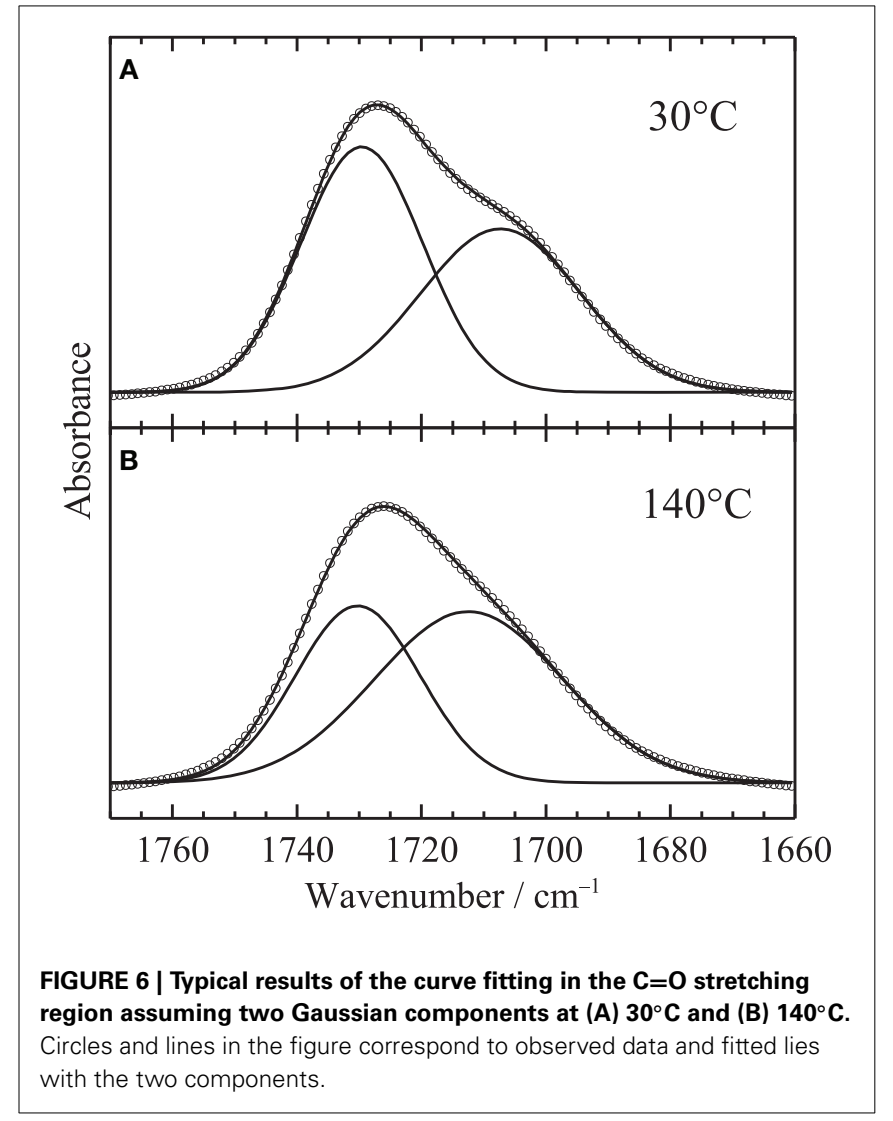

In order to clarify the spectral variations in the O-H stretching region, the spectral shapes in the region were fitted using the following Gaussian functions:

$$
A(\nu)=\sum_{i} h_{i} \exp \left(-4 \ln 2 \frac{\left(\nu-v_{i}\right)^{2}}{w_{i}^{2}}\right)
$$

were, $h_{i}, v_{i}$ and $w_{i}$ are peak height, peak position and peak width, respectively. Figure 3 shows the fitting results at (A) 30 and (B) $140^{\circ} \mathrm{C}$, respectively. All the spectra were well fitted assuming three Gaussian contributions, since the bands at 3666 and 3624 are very weak. Figure 4 depicts the fitting parameters for the O-H stretching region plotted as a function of temperature. Variations of the peak position and the peak width are relatively small, while those of peak height or area intensity, which is calculated as

$$
A_{i}=\int A_{i}(\nu) \mathrm{d} \nu
$$

are intense. The intensity variation of the band at $3434 \mathrm{~cm}^{-1}$, which is assigned to the first overtone of the $\mathrm{C}=\mathrm{O}$ stretching, is not clearly identified. In contrast, the intensity of the band at $3320 \mathrm{~cm}^{-1}$ gradually decreases with increasing temperature, while that at $3534 \mathrm{~cm}^{-1}$ gradually increases. It should be noted that the intensity variations at 3320 and $3534 \mathrm{~cm}^{-1}$ are not discontinuous with temperature at the glass transition temperature of $80^{\circ} \mathrm{C}$. 


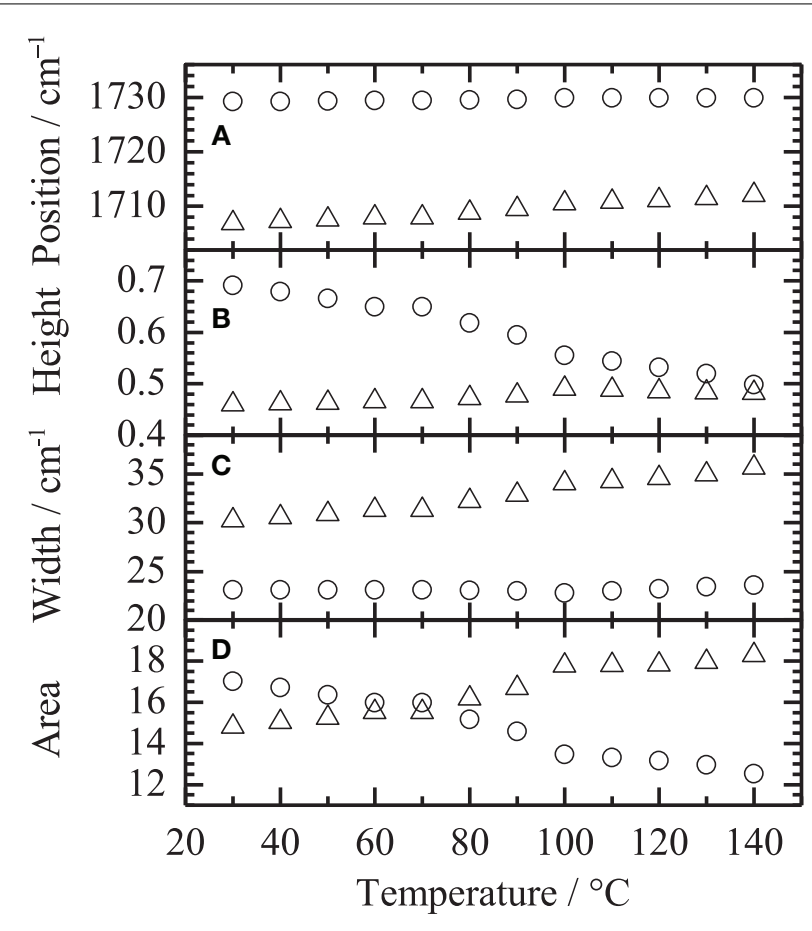

FIGURE 7 | Fitting parameters of (A) peak position, (B) peak height, (C) peak width and $(D)$ area intensity in the $C=0$ stretching region plotted as a function of temperature. Symbols of circle and triangle correspond to the bands around 1730 and $1703 \mathrm{~cm}^{-1}$, respectively.

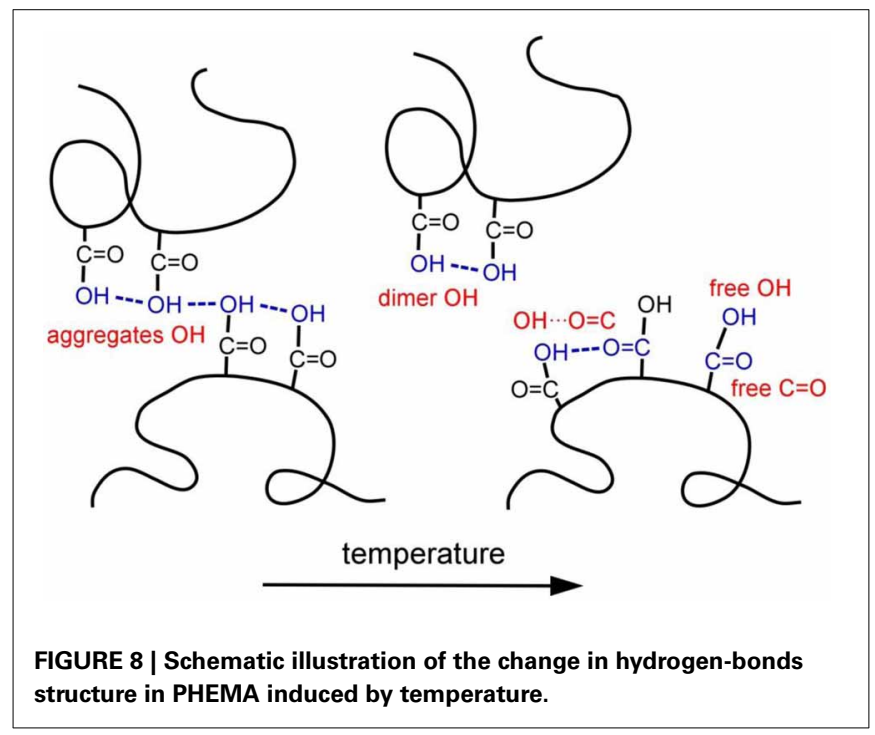

\section{C=0 STRETCHING REGION}

Figure 5A shows the temperature-dependent IR spectra of PHEMA in the $\mathrm{C}=\mathrm{O}$ stretching region (close up of Figure 1). Second derivative spectra and peak positions of the second derivative spectra are also plotted in Figures 5B,C, respectively. Two contributions around 1730 and $1703 \mathrm{~cm}^{-1}$ are identified in the $\mathrm{C}=\mathrm{O}$ stretching region. Assignments of the two bands given in our previous study (Morita et al., 2009) are summarized in
Table 2 | Typical glass transition temperature for poly(acrylate)s (Morita et al., 2004).

\begin{tabular}{llc}
\hline & Side chain structure & $\begin{array}{c}\text { Typical glass } \\
\text { transition } \\
\text { temperature/ }{ }^{\circ} \mathbf{C}\end{array}$ \\
\hline $\begin{array}{l}\text { Poly(2-methoxyethyl } \\
\text { acrylate) (PMEA) }\end{array}$ & $-\mathrm{COO}\left(\mathrm{CH}_{2}\right)_{2} \mathrm{OCH}_{3}$ & -50 \\
$\begin{array}{l}\text { Poly(ethyl acrylate) (PEA) } \\
\text { Poly(n-butyl }\end{array}$ & $-\mathrm{COOCH}_{2} \mathrm{CH}_{3}$ & -24 \\
$\begin{array}{l}\text { methacrylate) (PBMA) } \\
\text { Poly(2-hydroxyethyl } \\
\text { methacrylate) (PHEMA) }\end{array}$ & $-\mathrm{CH}_{3},-\mathrm{COO}\left(\mathrm{CH}_{2}\right)_{3} \mathrm{CH}_{3}$ & 20 \\
$\begin{array}{l}\text { Poly(methyl } \\
\text { methacrylate) (PMMA) }\end{array}$ & $\left.-\mathrm{CH}_{3},-\mathrm{COO}_{2}\right)_{2} \mathrm{OH}$ & 80 \\
\hline
\end{tabular}

Table 1. In order to clarify the spectral variations, the shapes in the region were fitted by two Gaussian components. Figure 6 shows the fitting results at (A) 30 and $(B) 140^{\circ} \mathrm{C}$, respectively. All the spectra were well fitted assuming two Gaussian contributions. Figure 7 depicts the fitting parameters for the $\mathrm{C}=\mathrm{O}$ stretching region plotted as function of temperature. The peak position of the band around 1730 scarcely changed with temperature, whereas that around $1703 \mathrm{~cm}^{-1}$ shifts toward to the higher wavenumber as similar to the peak position evaluated by the second derivatives as shown in Figure 5C. The peak width of the band at 1730 also scarcely changed, while that at $1703 \mathrm{~cm}^{-1}$ becomes broad with increasing temperature. It is of particular to note that the peak height or the area intensity of the band at $1703 \mathrm{~cm}^{-1}$ assigned to hydrogen-bonded $\mathrm{C}=\mathrm{O}$ discontinuously increases above the glass transition temperature of $80^{\circ} \mathrm{C}$, whereas that at $1730 \mathrm{~cm}^{-1}$ assigned to free $\mathrm{C}=\mathrm{O}$ discontinuously decreases at the temperature.

\section{DISCUSSION}

An evidence of gradual dissociation of the $\mathrm{OH} \cdots \mathrm{OH}$ type of hydrogen-bonds with increasing temperature was found in the $\mathrm{O}-\mathrm{H}$ stretching region. In contrast, it was found in the $\mathrm{C}=\mathrm{O}$ stretching region that association of the $\mathrm{C}=\mathrm{O} \cdots \mathrm{HO}$ type of hydrogen-bond occurs discontinuously above the glass transition temperature. The second derivative spectra in the $\mathrm{O}-\mathrm{H}$ stretching region revealed that the free $\mathrm{OH}$ appears above the glass transition temperature.

A schematic illustration of the change in hydrogen-bonds structure in PHEMA induced by temperature speculated from the spectral variations is described in Figure 8. At ambient temperature, $53.7 \%$ of the $\mathrm{OH}$ groups in the side chain terminal are associated with each other via the $\cdots \mathrm{OH} \cdots \mathrm{OH} \cdots \mathrm{OH} \cdots$ type of hydrogen-bonds. As a result, mobility of the main chain is expected to be suppressed by the non-covalent interactions among the side chains. However, the aggregates $\mathrm{OH}$ are easily dissociated by increasing temperature. At the glass transition temperature, which relates to the mobility of polymer main chain, the $\mathrm{OH}$ groups which dissociated with the other $\mathrm{OH}$ groups are associated with the $\mathrm{C}=\mathrm{O}$ groups with the $\mathrm{OH} \cdots \mathrm{O}=\mathrm{C}$ type of hydrogen-bond. It is likely that the mobility of the main chain 
is induced by the change in the hydrogen-bonds structure at the glass transition temperature.

Glass transition temperature for analogous poly(acrylate)s are generally lower than that for PHEMA as summarized in Table 2 (Morita et al., 2004). Only glass transition temperature for PMMA is higher than that for PHEMA because of non-bulky side chain, which enhances the main chain interaction. Glass transition temperature for PHEMA hydrogels is reduced by increasing a content of water in the matrix (Roorda et al., 1988). These also support the conclusion that the mobility of the PHEMA main chain is induced by the dissociation of the $\mathrm{OH} \cdots \mathrm{OH}$ type of hydrogen-bonds among the side chains, since water molecules also hydrated to both $\mathrm{OH}$ and $\mathrm{C}=\mathrm{O}$ groups in the PHEMA side chain via the $\mathrm{OH} \cdots \mathrm{OH}$ and $\mathrm{C}=\mathrm{O} \cdots \mathrm{HO}$ types of hydrogenbonds (Tsuruta, 2010). Miwa et al. found the evidences of strong $\mathrm{OH} \cdots \mathrm{OH}$ and $\mathrm{C}=\mathrm{O} \cdots \mathrm{HO}$ types of hydrogen-bonds between the PHEMA side chain and water molecule using NMR spectroscopy (Miwa et al., 2010). In the case of PHEMA hydrogels, it is likely that the hydrogen-bonds among the PHEMA side chains are partially inhibited by water molecules. As a result, glass transition temperature for PHEMA is reduced by the content of water.

\section{REFERENCES}

Brunsveld, L., Folmer, B., Meijer, E., and Sijbesma, R. (2001). Supramolecular polymers. Chem. Rev. 101, 4071-4098. doi: 10.1021/cr990125q

Ferreira, L., Vidal, M., and Gil, M. (2000). Evaluation of poly(2-hydroxyethyl methacrylate) gels as drug delivery systems at different $\mathrm{pH}$ values. Int. J. Pharm. 194, 169-180. doi: 10.1016/S0378-5173(99)00375-0

Jeffrey, G. A. (1997). An Introduction to Hydrogen Bonding. New York, NY: Oxford University Press.

Kristiansson, O. (1999). Investigation of the $\mathrm{OH}$ stretching vibration of CD3 OH in CCl4. J. Mol. Struct. 477, 105-111. doi: 10.1016/S0022-2860(98)00591-2

Marechal, Y. (2007). The Hydrogen Bond and the Water Molecule: The Physics and Chemistry of Water, Aqueous and Bio-Media. Amsterdam: Elsevier.

Miwa, Y., Ishida, H., Tanaka, M., and Mochizuki, A. (2010). 2H-NMR and 13CNMR study of the hydration behavior of poly(2-methoxyethyl acrylate), poly(2hydroxyethyl methacrylate) and poly(tetrahydrofurfuryl acrylate) in relation to their blood compatibility as biomaterials. J. Biomater. Sci. -Polym. Ed. 21, 1911-1924. doi: 10.1163/092050610X489682

Montheard, J.-P., Chatzopoulos, M., and Chappard, D. (1992). 2-Hydroxyethyl methacrylate (HEMA): chemical properties and applications in biomedical fields. J. Macromol. Sci. Part C Polym. Rev. 32, 1-34. doi: $10.1080 / 15321799208018377$

Morita, S., and Kitagawa, K. (2010). Temperature-dependent structure changes in Nafion ionomer studied by PCMW2D IR correlation spectroscopy. J. Mol. Struct. 974, 56-59. doi: 10.1016/j.molstruc.2009.12.040

Morita, S., Kitagawa, K., Noda, I., and Ozaki, Y. (2008). Perturbation-correlation moving-window 2D correlation analysis of temperature-dependent infrared spectra of a poly(vinyl alcohol) film. J. Mol. Struct. 883, 181-186. doi: 10.1016/j.molstruc.2007.12.004
Morita, S., Kitagawa, K., and Ozaki, Y. (2009). Hydrogen-bond structures in poly(2-hydroxyethyl methacrylate): infrared spectroscopy and quantum chemical calculations with model compounds. Vib. Spectrosc. 51, 28-33. doi: 10.1016/j.vibspec.2008.09.008

Morita, S., Ye, S., Li, G. F., and Osawa, M. (2004). Effect of glass transition temperature $(\mathrm{Tg})$ on the absorption of bisphenol $\mathrm{A}$ in poly(acrylate)s thin films. Vib. Spectrosc. 35, 15-19. doi: 10.1016/j.vibspec. 2003.11.020

Ohno, K., Shimoaka, T., Akai, N., and Katsumoto, Y. (2008). Relationship between the broad $\mathrm{OH}$ stretching band of methanol and hydrogen-bonding patterns in the liquid phase. J. Phys. Chem. A 112, 7342-7348. doi: 10.1021/jp $800995 \mathrm{~m}$

Perova, T. S., Vij, J. K., and Xu, H. (1997). Fourier transform infrared study of poly(2-hydroxyethyl methacrylate) PHEMA. Colloid Polym. Sci. 275, 323-332. doi: 10.1007/s003960050089

Roorda, W. E., Bouwstra, J. A., De Vries, M. A., and Junginger, H. E. (1988). Thermal behavior of poly hydroxy ethyl methacrylate (pHEMA) hydrogels. Pharm. Res. 5, 722-725. doi: 10.1023/A:1015912028859

Tanaka, M., Mochizuki, A., Ishii, N., Motomura, T., and Hatakeyama, T. (2002). Study of blood compatibility with poly(2-methoxyethyl acrylate). Relationship between water structure and platelet compatibility in poly $(2$ methoxyethylacrylate-co-2-hydroxyethylmethacrylate). Biomacromolecules 3, 36-41. doi: 10.1021/bm010072y

Tsuruta, T. (2010). On the role of water molecules in the interface between biological systems and polymers. J. Biomater. Sci. Polym. Ed. 21, 1831-1848. doi: 10.1163/092050610X488269

Watanabe, A., Morita, S., and Ozaki, Y. (2006). Study on temperaturedependent changes in hydrogen bonds in cellulose I beta by infrared spectroscopy with perturbation-correlation moving-window two-dimensional correlation spectroscopy. Biomacromolecules 7, 3164-3170. doi: 10.1021/ bm0603591

Watanabe, A., Morita, S., and Ozaki, Y. (2007). Temperature-dependent changes in hydrogen bonds in cellulose I alpha studied by infrared spectroscopy in combination with perturbation-correlation moving-window two-dimensional correlation spectroscopy: comparison with cellulose I beta. Biomacromolecules 8, 2969-2975. doi: 10.1021/bm700678u

Conflict of Interest Statement: The author declares that the research was conducted in the absence of any commercial or financial relationships that could be construed as a potential conflict of interest.

Received: 07 January 2014; paper pending published: 05 February 2014; accepted: 24 February 2014; published online: 12 March 2014.

Citation: Morita S (2014) Hydrogen-bonds structure in poly(2-hydroxyethyl methacrylate) studied by temperature-dependent infrared spectroscopy. Front. Chem. 2:10. doi: 10.3389/fchem.2014.00010

This article was submitted to Polymer Chemistry, a section of the journal Frontiers in Chemistry.

Copyright (C) 2014 Morita. This is an open-access article distributed under the terms of the Creative Commons Attribution License (CCBY). The use, distribution or reproduction in other forums is permitted, provided the original author(s) or licensor are credited and that the original publication in this journal is cited, in accordance with accepted academic practice. No use, distribution or reproduction is permitted which does not comply with these terms. 